\title{
Choroidal Osteoma with Choroidal Neovascular Membrane treated with Anti- vascular Endothelial Growth Factor: A Rare Case with Review of Literatures
}

\author{
Phuntsho Dorji ${ }^{10}$, Nor Tshering Lepcha ${ }^{1}$, Raba Thapa ${ }^{2}$ \\ ${ }^{1}$ Gyalyum Kesang Choeden Wangchuck National Eye Centre, Thimphu, Bhutan \\ ${ }^{2}$ Tilganga Institute of Ophthalmology, Kathmandu, Nepal
}

\begin{abstract}
Introduction: Choroidal osteoma, usually unilateral, is a rare benign tumor of choroid. It is predominantly seen in young females.

Case: We report a case of a 35-year-old female with unilateral choroidal osteoma associated with choroidal neovascular membrane (CNVM). The diagnosis was confirmed with clinical examination, ocular ultrasonography, fundus fluorescein angiography and macular optical coherence tomography. Choroidal neovascular membrane improved with 3 doses of bevacizumab, an anti-vascular endothelial growth factors (Anti-VEGF).

Conclusion: Anti-VEGF monotherapy can be a cost effective primary modality of treatment for choroidal neovascular membrane secondary to choroidal osteoma.

Key words: Anti-vascular endothelial growth factor, Choroidal neovascular membrane, Choroidal osteoma.
\end{abstract}

\section{INTRODUCTION}

Choroidal osteoma is an ossifying tumour of choroid which is usually unilateral. It is a benign condition and most commonly seen in young females. Choroidal neovascular membrane (CNVM) can occur in choroidal osteoma (Gass JDM et al, 1978). CNVM can be treated effectively with laser, photodynamic therapy and anti-vascular endothelial growth factors (VEGF) (Ramzi M A et al, 2014). Here we report a rare case of choroidal osteoma with CNVM successfully treated with anti-VEGF.

\begin{tabular}{|c|c|}
\hline Financial Interest : Nil & Received : 04.12.2020 \\
\hline Conflict of Interest : Nil & Accepted : 10.03.2021 \\
\hline \multicolumn{2}{|l|}{ Corresponding Author } \\
\hline \multicolumn{2}{|l|}{ Dr. Phuntsho Dorji } \\
\hline \multicolumn{2}{|c|}{$\begin{array}{l}\text { Gyalyum Kesang Choeden Wangchuck National Eye Centre, } \\
\text { Thimphu, Bhutan. }\end{array}$} \\
\hline E-mail: pdorji@mrrh.gov.b & \\
\hline
\end{tabular}

Access this article online

Website: www.nepjol.info/index.php/NEPJOPH DOI: https://doi.org/10.3126/nepjoph.v13i2.33218 Copyright $\odot 2021$ Nepal Ophthalmic Society ISSN: 2072-6805, E-ISSN: 2091-0320 This work is licensed under a Creative Commons Attribution-NonCommercial-NoDerivatives 4.0 International License (CC BY-NC-ND). 


\section{CASE REPORT}

A 35-year-old female presented with decreased vision in the left eye for 5 months. It was insidious in onset, painless and progressive. There was no history of trauma and other associated ocular symptoms.

On examination, her best corrected visual acuity (BCVA) was 6/6 in right eye and 6/36 in left eye. The intraocular pressure was normal in both eyes. The lid and adnexa were normal. Slit lamp examination of the anterior segment were unremarkable in both eyes.

The media was clear with normal optic disc in both eyes. The right eye fundus was normal. In the left eye there was a subretinal yellowish white lesion measuring about 10 disc diameter involving the fovea, inferior arcade and inferotemporal quadrant of fundus (Figure 1). There was neurosensory detachment with subretinal fluid at the macula. Ultrasound B scan showed thickening of choroid with orbital back shadowing causing pseudo-optic nerve head shadow (Figure 2). There was high hyperreflectivity at the level of choroid in ultrasound A scan. The optical coherence tomography (OCT) showed normal vitreoretinal interface, altered foveal contour with shallow neurosensory detachment. The central macular thickness (CMT) was 262 micrometre. There were multiple intraretinal cystic changes with subretinal fluid just temporal to fovea in OCT (Figure 3).
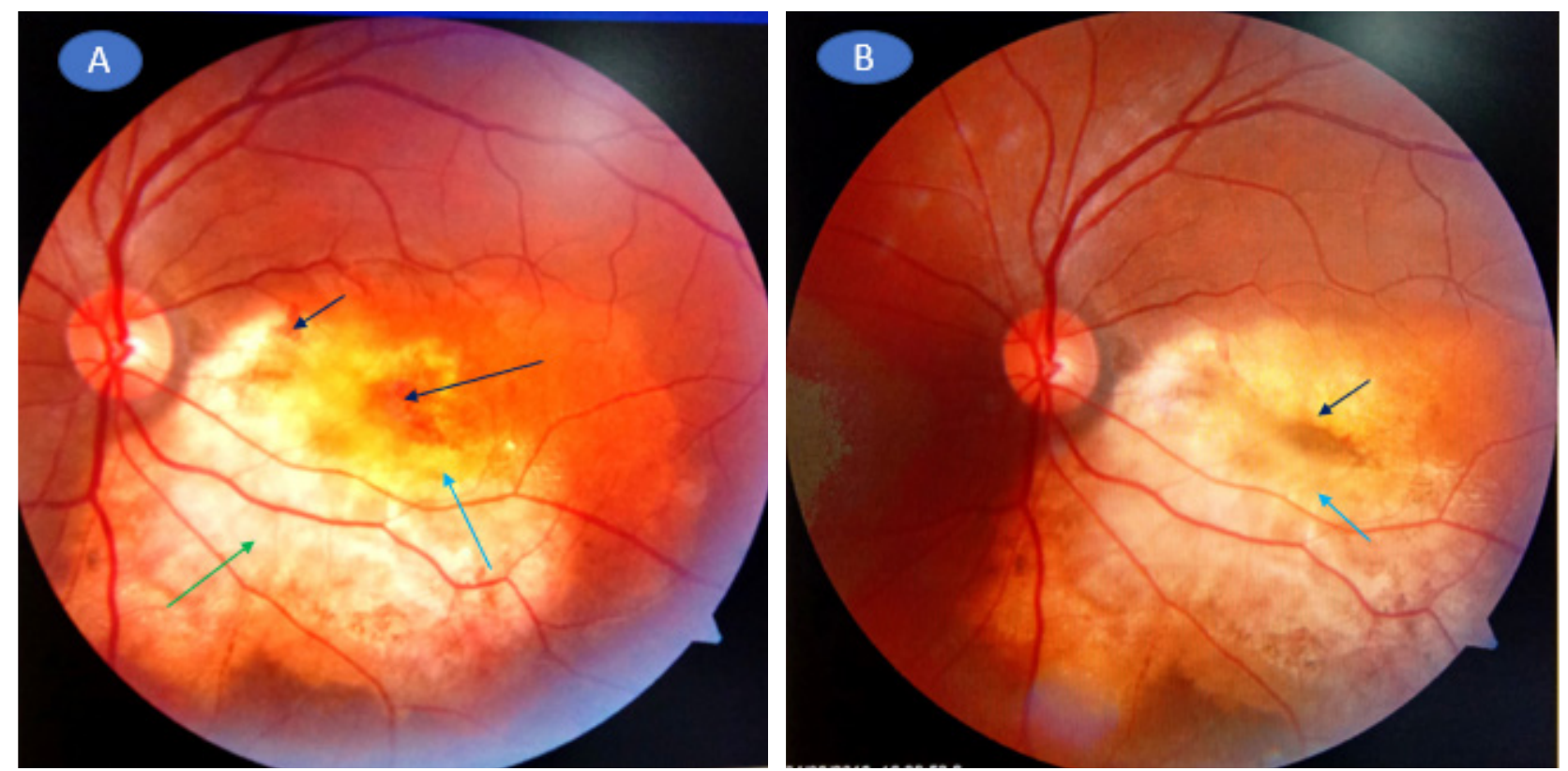

Figure 1: (A) Subretinal yellowish white lesion (green arrow), sub-retinal hemorrhage (dark blue arrow), yellowish membrane (light blue arrow) at presentation.

(B) Resolved subretinal hemorrhage (dark blue arrow) and resolving subretinal membrane (light blue arrow) after treatment. 

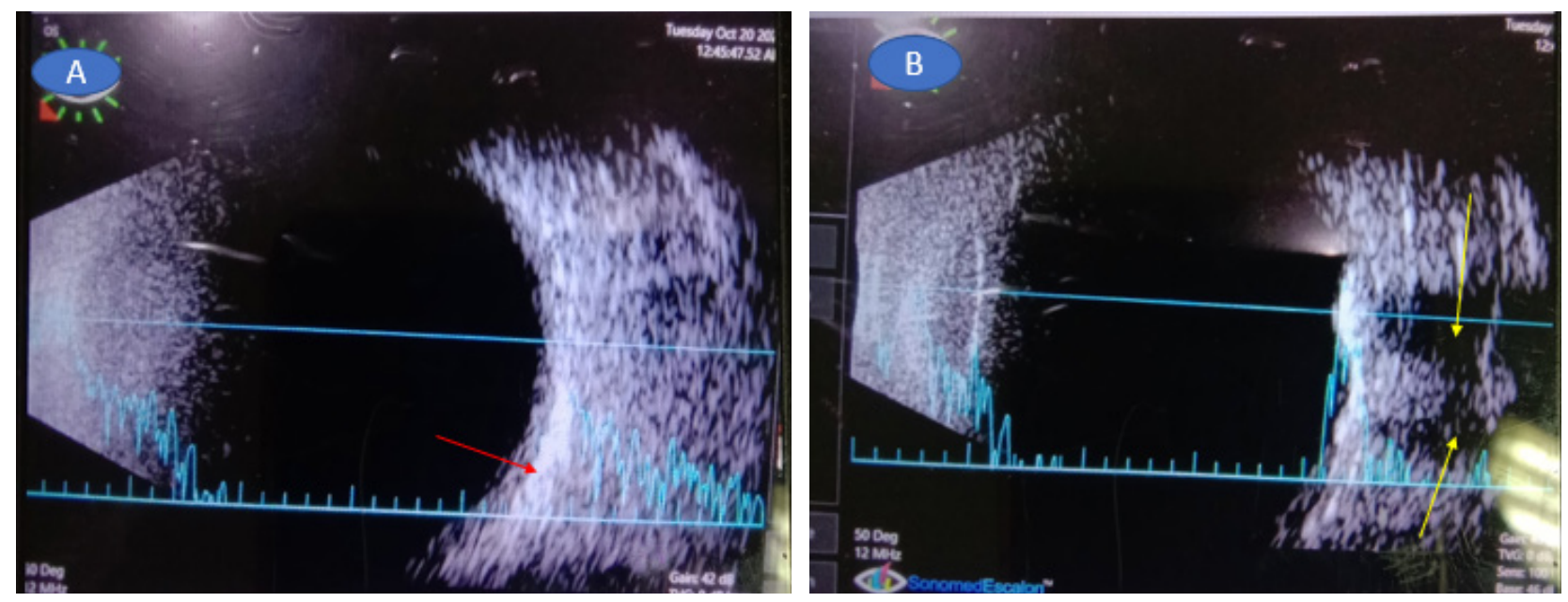

Figure 2: (A) B scan showing high hyperreflectivity at the level of choroid (red arrow) and (B) choroidal lesion showing orbital back shadowing pseudo optic nerve (yellow arrow).
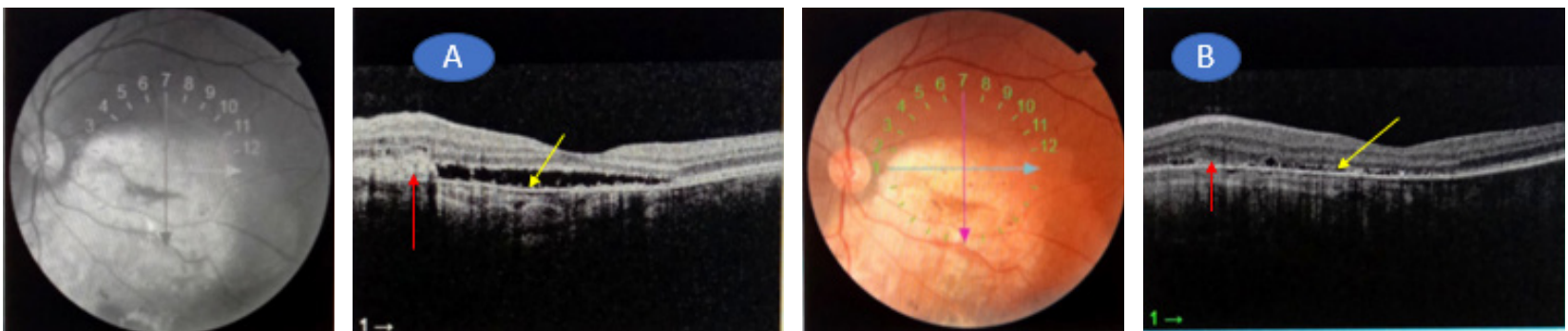

Figure 3: (A) OCT showing subretinal hyperreflective material suggesting CNVM (red arrow) and subretinal fluid (yellow arrow) at presentation. (B) Resolved CNVM (red arrow) with subretinal fluid (yellow arrow) after treatment.

The fundus fluorescein angiography (FFA) of the left eye showed early hypofluorescence with late hyperfluorescence suggesting active CNVM (Figure 4). With these investigation findings, diagnosis of choroidal osteoma with CNVM was confirmed. She was treated with one dose of intravitreal anti-VEGF ranibizumab (Accentrix $0.5 \mathrm{mg} / 0.05 \mathrm{ml}$ ) followed by two doses of bevacizumab (Avastin $1.25 \mathrm{mg} / 0.05$ $\mathrm{ml}$ ) at one month intervals. All the intravitreal injections were given under strict aseptic precautions under topical anaesthesia. The BCVA improved to $6 / 9$ from 6/36 in the left eye with complete resolution of subretinal fluid after three doses of Anti-VEGF. The patient followed up every month consecutively for five months after which there was a gap of seven months due to COVID-19 pandemic. Her vision was stable with $6 / 9$ in the left eye on her last follow up. Patient was followed up for a total of 10 months after the last dose of intravitreal bevacizumab.

Other choroidal lesions like amelanotic choroidal melanoma, amelanotic choroidal nevus and metastatic choroidal carcinoma can have similar fundus presentation. 

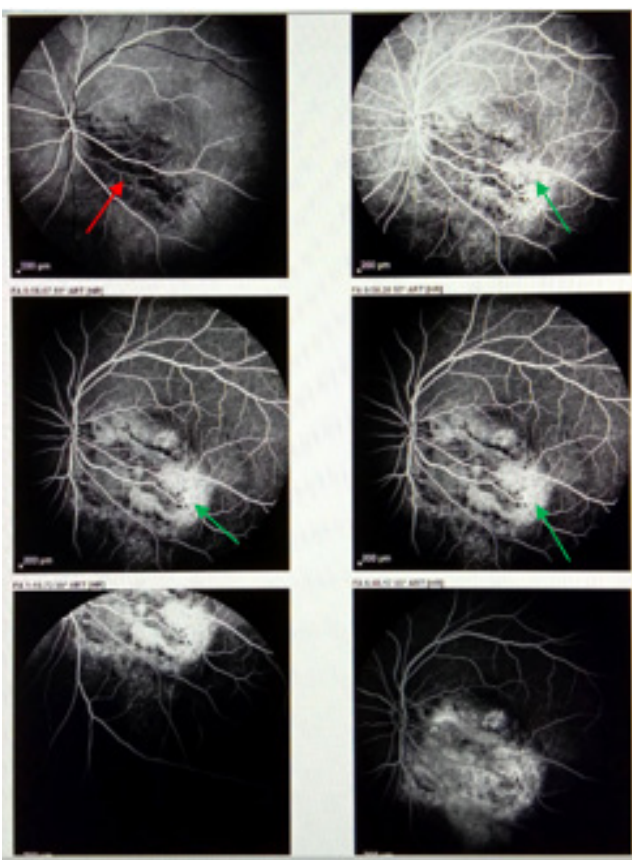

Figure 4: FFA showing early hypofluorescence (red arrow) and hyperfluorescence on subsequent angiography (green arrow).

An amelanotic choroidal melanoma is usually seen in middle age to elderly group of people with no sex predilection. The lesion in amelanotic melanoma is highly elevated, has an ill defined margin with yellowish brown in colour. This is in contrast to choroidal osteoma which is commonly seen in young females and the lesion is minimally elevated, with a well defined margin with yellowish white to orange in colour. In choroidal osteoma ultrasound B and A scan shows high choroidal hyperreflectivity with orbital backshadowing (pseudo optic nerve) which is not seen in amelanotic choroidal melanoma.

An amelanotic nevus can have a similar fundus picture like choroidal osteoma. However it is yellowish orange in color, less distinct margin and has no sex predilection. There is no choroidal high hyperreflectivity with backshadowing as seen in choroidal osteoma.

Metastatic choroidal carcinoma should also be excluded in a patient with choroidal osteoma. It can be bilateral or unilateral depending on the type of systemic tumour. Choroidal metastasis can be unifocal or multifocal and it is usually located in the post equatorial region. The lesion has an ill defined margin, more elevation and is associated with subretinal fluid. Systemic evaluation was done along with ultrasonography of the abdomen and pelvis, chest X-ray and liver function test to rule out metastatic lesions.

Therefore, it is important to rule out amelanotic choroidal melanoma, amelanotic choroidal nevus and metastatic choroidal carcinoma in a patient with choroidal osteoma. 


\section{DISCUSSION}

A choroidal osteoma is a rare benign choroidal tumour. It was first described by Gass in 1978 (Gass JDM et al, 1978). It is composed of mature bone and almost involves the full thickness of choroid. It is mostly unilateral (75-80\%) and predominantly seen in young females (Gass JDM et al,1978, Shields et al, 1988 and Paul A et al, 2016). Similar to these literatures our case is a young female with a unilateral presentation.

Choroidal osteoma typically presents as yellow- white to orange-red elevated subretinal lesion. It is noted mostly at juxtapapillary or peripapillary region. Decreased vision in choroidal osteoma could be due to atrophy of retinal pigment epithelium, neurosensory detachment and CNVM. CNVM is seen in 31$47 \%$ of cases of choroidal osteoma (Ramzi MA et al, 2014). As reported in literature, decreased vision in our case was due to CNVM associated with neurosensory detachment. Multimodal imaging like B scan, A scan and CT scan aid in establishing the diagnosis. Other imaging like OCT and FFA helps to confirm the presence of CNVM. In our case, there were typical features of choroidal osteoma in ultrasound B scan and A scan. The presence of CNVM was confirmed with OCT and FFA as reported in other studies (Ramzi MA et al, 2014 and Francisco OlguinManriquez et al, 2018 ).We should suspect CNVM if patient with choroidal osteoma presents with recent onset deterioration of vision.

Usually no treatment is required for choroidal osteoma. The general prognosis of choroidal osteoma depends on the location of lesion and presence of neovascularization. Patients can have good vision if the lesion is extrafoveal. If it is subfoveal and associated with CNVM patients can have sudden deterioration of vision. In long standing cases without CNVM the patient can have gradual decrease in vision due to retinal pigment epithelium and neurosensory atrophy (Shields et al, 1988). Treatment is initiated only when there is presence of CNVM. The treatment options available are laser photocoagulation, photodynamic therapy (PDT), transpupillary thermotherapy (TTT) and Anti-VEGF (Ramzi M A et al, 2014). There is poor uptake of laser due to RPE depigmentation in choroidal osteoma. PDT requires multiple treatments, costly and vision may worsen even after treatment. The visual outcome after TTT is not favorable. As per the reports of Ahmadieh et al, 2007 and Narayanan et al, 2008 intravitreal bevacizumab has shown good outcome in CNVM secondary to choroidal osteoma. Other literature also reported a successful outcome with bevacizumab (Agarwal M et al, 2014; Song JH et al, 2010 and Pandey $\mathrm{N}$ et al, 2010). So our case was treated with intravitreal bevacizumab and the response was very good. There was regression of CNVM as evidenced by OCT and good improvement in BCVA from 6/36 to 6/9 after three doses of Anti-VEGF. Patient received a total of three doses of intravitreal Anti-VEGF that included one dose of ranibizumab and two doses of bevacizumab. The anti-VEGF was changed to bevacizumab from ranibizumab as ranibizumab was not available in our country. The vision was 
stable and no subretinal fluid during subsequent follow up period of 10 months. There are reports of CNVM due to choroidal osteoma treated effectively with PDT (A D Singh et al, 2005). Considering the high cost of ranibizumab and PDT, bevacizumab still remains the first choice of treatment in a low resource setting. Hence our case report can be an additional report of favorable outcome of bevacizumab in choroidal osteoma with CNVM.

\section{CONCLUSION}

Intravitreal bevacizumab can be a good option in treatment of CNVM secondary to choroidal osteoma in a low resource setting. However we recommend a large case series and long term follow up to assess the efficacy of bevacizumab in these cases.

\section{REFERENCES}

Ahmadieh H, Vafi N. Dramatic response of choroidal neovascularization associated with choroidal osteoma to the intravitreal injection of bevacizumab (2007). Graefes Arch Clin Exp Ophthalmol;245:17313. doi: 10.1007/s00417007-0636-z; PMid:17653753

Agarwal M, Kantha M, Mayor R, Venkatesh R, Shroff CM (2014). Bilateral choroidal osteoma with choroidal neovascular membrane treated with bevacizumab in a child. Middle East Afr J Ophthalmol;21:265-8. doi: 10.4103/0974-9233.134692; PMid:25100914

Gass J.D.M, Guerry, R K, Jack R.L and Harris G(1978). Choroidal osteoma. Archives of Ophthalmology;96(3):428-35. doi: 10.1001/archopht.1978.03910050204002; PMid:629679

Narayanan R, Shah VA (2008). Intravitreal bevacizumab in the management of choroidal neovascular membrane secondary to choroidal osteoma. Eur J Ophthalmol;18:4668. doi: 10.1177/112067210801800327; PMid:18465736

Olguin-Manriquez F, Bety Enriquez A,Crim Nicholas et al (2018). Multimodal imaging in choroidal osteoma.Int J Retina Vitreous;4:30. doi: 10.1186/s40942-018-0132-0; PMid:30128167

Pandey N, Guruprasad A (2010). Choroidal osteoma with choroidal neovascular membrane: Successful treatment with intravitreal bevacizumab. Clin Ophthalmol;4:10814. doi: 10.2147/OPTH.S13730; PMid:20957052

Paul A, Mani LS, Ramesh R, Shahi A (2016).Choroidal osteoma: An atypical case. Kerala J Ophthalmol;28:145-7. doi: 10.4103/kjo.kjo_4_17

Ramzi M. Alameddine, Ahmad M. Mansour and Eman Kahtani (2014). Review of choroidal osteomas.Middle East Afr J Ophthalmol;21(3): 244-50. doi: 10.4103/0974-9233.134686; PMid:25100910

Shields CL, Shields JA, Augsburger JJ (1988). Choroidal osteoma. Surv of Ophthalmol;3(1):17-27. doi: 10.1016/00396257(88)90069-0

Shields CL, Sun H, Demirci H, Shields JA (2005).Factors predictive of tumor growth, tumor decalcification, choroidal neovascularization and visual outcome in 74 eyes with choroidal osteoma. Arch Ophthalmol;123:165866. doi: 10.1001/archopht.123.12.1658; PMid:16344436

Singh AD, Talbot JF, Rundle PA and Rennie IG (2005). Choroidal neovascularization secondary to choroidal osteoma: successful treatment with photodynamic therapy. Eye;19:482-84. doi: 10.1038/sj.eye.6701475; PMid:15286675

Song JH, Bae JH, Rho MI, Lee SC (2010). Intravitreal bevacizumab in the management of subretinal fluid associated with choroidal osteoma.Retina;30:94551. doi: 10.1097/IAE.0b013e3181c720ca; PMid:20531145 